\title{
Addressing the Business of Discharge: Building a Case for an Electronic Discharge Summary
}

\author{
Michelle Mourad, mo ${ }^{1}$ \\ Russell Cucina, mD, ms ${ }^{1,2}$ \\ Rajiv Ramanathan, $\mathrm{ms}^{\mathrm{MBA}}{ }^{1}$ \\ Arpana R. Vidyarthi, mo ${ }^{1}$
}

\author{
${ }^{1}$ Department of Medicine, Division of Hospital Medicine, University of California San Francisco, \\ San Francisco, California. \\ ${ }^{2}$ Department of Information Technology, UCSF Medical Center, San Francisco, California.
}

Disclosure: Nothing to report.

Hospitalists are increasingly involved in implementing quality improvement initiatives around patient safety, clinical informatics, and transitions of care, but may lack expertise in promoting these important interventions. Developing a sound business case is essential to garnering support and resources for any quality improvement initiative. We present a framework for developing a business case using a structured approach to exploring qualitative and quantitative costs and benefits and describe its application in the experience of developing an electronic discharge summary at the University of California San Francisco (UCSF). At our institution, we found that the primary financial benefits are the cost reductions in eliminating transcription needs and decreasing billing delays, as well as reducing the cost of tracking completion of and dissemination of discharge summaries. Costs incurred from a new information technology (IT) infrastructure, programmer time, maintenance and training must also be accounted for. While benefits may be apparent to front line providers (improved communication, efficiency of data transfer, and increased referring physician satisfaction), implementing and sustaining such an innovation depends on articulating a sound business case with a detailed costbenefit analysis to institutional decision making. Journal of Hospital Medicine 2011;6:37-42. @ 2010 Society of Hospital Medicine.

KEYWORDS: continuity of care, hospital administration, hospital discharge, medical informatics.

Delivering the highest possible quality of care is among the top priorities of all medical centers. That said, any quality innovation must be seen as adding value from a variety of perspectives. Especially in the current economic climate, a sound business case is paramount to the advancement of any quality innovation. Given the nature of their work, hospitalists are ideally suited to undertake system improvement innovations. To assist hospitalists in successfully implementing quality and safety initiatives, we have designed a framework of elements required for a business case. We describe our experience developing and implementing an electronic discharge summary and utilize a structured framework to articulate the business case for its implementation.

\section{Defining a Business Case Framework}

A business case is a structured proposal outlining the qualitative and quantitative factors that justify a course of action. An effective business case for a quality improvement initiative articulates how both factors are aligned with preexisting organizational goals. In modeling the business case framework for the electronic discharge summary, Figure 1 outlines the qualitative and quantitative costs and benefits that can affect institutional decision making.

\section{Organizational Aims and Financial Impact: Determining Costs and Benefits}

Organizational goals drive decision making and resource allocation at all levels. As priorities change with time, understanding which predominate in an organization will be essential to building a business case. Institutions may be more willing to adopt expensive innovations if they are justified by progress toward the qualitative organizational goals. Figure 1 demonstrates several institutional goals both qualitative (provider satisfaction, quality improvement, and institutional reputation) and quantitative (cost avoidance, cost savings, and revenue generation) that could drive the decision making for an electronic discharge summary. After examining how an initiative aligns with institutional aims, the next step is to weigh the benefits against the potential costs. Costs in our example include not only the quantitative financial investment in information technology (IT) infrastructure, personnel and maintenance, but also may include qualitative costs such as loss of staff efficiency and redundant documentation. Costs and savings will be geographically variable and depend on the institutional framework, eg, the existing system for medical records, institutional patient payer mix, type of payment structure (global vs. utilization based*), and reimbursement rates. While it may be impractical to account for every cost and savings resulting from the project implementation, every effort 


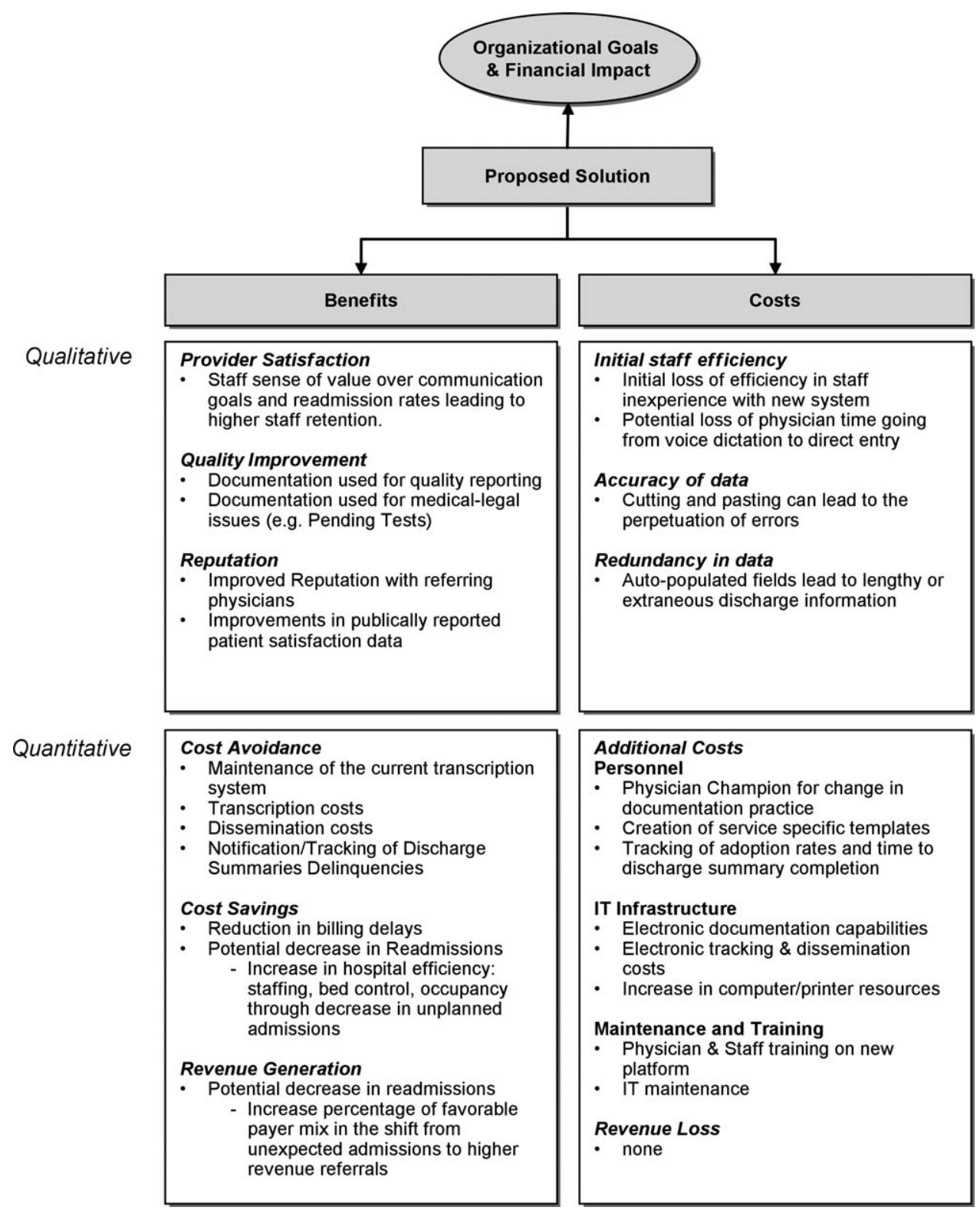

FIGURE 1. Applying the business case framework to electronic discharge summaries.

should be made to account for the key variables that make up the cost-benefit calculation.

\section{The Business Case for an Electronic Discharge Summary at University of California San Francisco (UCSF) Current State of Discharge Documentation at UCSF}

UCSF Medical Center is a 600-bed quaternary care academic institution that discharges approximately 100 patients per day. Our hospital discharge summary is used to document a patient's hospital course and post discharge plan, information necessary for continued care in the outpatient setting. Literature supports the potential for timely and relevant discharge summaries to improve care transitions, clinician satisfaction, and resource use. ${ }^{1}$ In 2008, however, the majority of our discharge summaries were completed greater than 14 days post discharge, in accordance with national practice. ${ }^{2}$ Despite Centers for Medicare \& Medicaid Services (CMS) and the Joint Commission discharge summary standards regarding content, ${ }^{3,4}$ most discharge summaries are composed using freeform dictation. ${ }^{2}$ Consequently, discharge summaries often lack critical information, ${ }^{5-7}$ and may not reach the correct outpatient provider in a timely manner. ${ }^{5,8-11}$

\section{Our Proposed Solution: E-Discharge}

As hospitals are increasingly implementing electronic medical records (EMR), ${ }^{12}$ there is a growing opportunity to efficiently and reliably incorporate information from the medical record into "electronic" or "database assisted" discharge 
materials. At UCSF the need to develop a system to document and communicate tests pending at discharge fueled the development of an electronic discharge summary. UCSF's vendor-supplied EMR lacks the ability to integrate electronic patient data into a progress note or discharge summary in a manner usable for physicians. Instead physicians are required to use a telephone voice dictation system, which is subsequently transcribed to text within 1 to 3 days. A separate software platform tracks attending signature of the transcribed text and automatically triggers dissemination through computerized fax and campus mail. The turnaround time for a discharge summary can be as long as 3 weeks. With the time involved and high cost of implementing new or more sophisticated versions of EMR, we chose to design a solution that would improve care for our patients in a more immediate and cost neutral fashion. Our goal was to create an affordable, electronic, systematized solution to produce both timely and relevant discharge summaries, in the hopes of improving communications with providers and thus patient outcomes.

In earlier work, UCSF developed UCSF Note Writer, a template-based documentation tool that uses web service to import data from the underlying database for provider documentation. $^{13}$ As a standardized template has been shown to improve quality of communication to both patients and referring providers, ${ }^{1,14,15}$ we developed a template in UCSF Note Writer with both free text and auto-populated fields for a discharge summary based on current guidelines. ${ }^{16-19}$ We encouraged the documentation of medication changes, changes in functional status and pending tests.

The adoption of such an electronic format has also been shown to improve the efficiency of discharge documentation over conventional dictation and transcription. ${ }^{1,20-22}$ While this change may be institution dependent, we employed strategies such as allowing the discharge summary to be initiated and updated throughout the hospital admission and unifying the discharge summary with the last day's progress note to facilitate timeliness. To promote efficiency, we allowed providers to import pertinent labs, microbiology, and in the future, the importation of pending tests. While the electronic format in itself does not promote timeliness, it incorporates the discharge summary into physician daily workflow and enables efficiency in data gathering and transfer. For outpatient providers who can access the EMR, any delay or potential fault in the delivery of the discharge materials is eliminated, while outside providers can receive copies through other rapid and reliable modes of electronic delivery (eg, EMR inbox notification) with an appropriate infrastructure.

\section{Application of the Business Framework to the Case for an Electronic Discharge}

Considering the potential improvements in care delivery, the argument for an electronic discharge summary may seem self-evident. To realize its implementation, however, it is necessary to consider other aspects of organizational decision making. We employed the following structure to articulate a robust and sound business case for e-discharge.

\section{Qualitative Benefits}

\section{Quality and Safety}

Publically reported data are often derived from hospital chart abstraction and may impact accreditation, reputation, and pay for performance programs. ${ }^{18,23,24}$ The discharge summary is a readily available source of information regarding discharge medications, patient instruction, and communication regarding pending tests. As such, its quality should be a priority for hospital decision makers. Electronic discharge summaries have the potential to reduce adverse events in the highrisk post-hospitalization period. ${ }^{1,25}$ As such they may improve outpatient physicians' ability to deliver relevant care, reduce preventable readmissions ${ }^{26}$ and reduce malpractice vulnerability $^{27}$ —all key drivers in organizational decision making.

\section{Patient Satisfaction}

Patients want to feel prepared for discharge by understanding the continuity of their care from the hospital to the outpatient setting. Discharge preparedness, commonly queried and reported in national patient satisfaction surveys, is low. ${ }^{28}$ Many electronic discharge summary platforms allow for translation into tailored patient instructions available to the patient in real time, helping to ensure that patients receive quality discharge education. ${ }^{29}$

\section{Referring Physician Satisfaction}

Poor discharge communication reduces referring physicians' satisfaction, which may discourage them from referring patients to the hospital or organization, having broader financial implications. $^{25,30}$ Even for medical centers with a busy emergency department, outpatient physician referrals and recommendations make up over $50 \%$ of an institution's admissions. ${ }^{31}$ An electronic discharge summary available in the EMR at the time of discharge, electronically transmitted to referring providers can impact the referral patterns of community physicians.

\section{Readmission}

Now publicly reported, readmission rates are another benchmark by which to judge hospital care. ${ }^{32}$ Patients with discharge summaries that are unavailable to outpatient providers, a very common occurance, ${ }^{2}$ have a higher trend toward readmission. ${ }^{26}$ Improved quality of care at the time of discharge resulting in fewer readmissions will better position hospitals to contend with potential Medicare reforms.

\section{Quantitative Benefits}

\section{IT Infrastructure: Transcription, Deficiency}

\section{Tracking, Dissemination}

Hospitals, including UCSF, use internal or external transcriptionists to transcribe dictated recordings into typed text at a substantial cost to large medical centers. Medical records staff also track both discharge summary completion and 
their dissemination to referring providers in compliance with regulatory mandates. ${ }^{4,33}$ The use of electronic documentation that relies on physician-direct entry and that automates dissemination and tracking of discharge documentation provides a potential cost savings to offset the costs of a new system. UCSF Medical Center discharges 100 patients per day and could conservatively avoid almost $\$ 500,000$ in transcription costs annually (Text Box 1). ${ }^{34}$

\section{Text Box 1}

UCSF Transcription costs:

Average cost/line for transcribed text: \$0.17

Average Lines in a discharge summary: 80

\# pts discharged/day: 100

Yearly costs $=\$ 496,400$

\section{Billing}

Delays in completion of discharge summaries result in billing delays when critical information required for coding is in the discharge summary. Deferred payment on long admissions can reach tens of thousands of dollars, representing a significant strain on medical center finances. Comprehensive electronic discharge materials may simplify coding through careful documentation and improve billing efficiency through rapid completion.

At our medical center, approximately $20 \%$ of billing is delayed due to incomplete discharge documentation. For a hospital that generates over \$1.4 billion dollars in billing revenue per year, this can translate into significant financial losses. Hospitals may have to borrow money or draw from existing resources to cover operative deficits created by a delay in the receipt of large payment. Lenders charge approximately $1 \%$ to $2 \%$ annual interest rate, which translates into $0.2 \%$ to $0.4 \%$ in billed costs that the hospital gives away to their lenders. Hospitals would be well served by eliminating delays in billing to improve revenue flow (Text Box 2).

\section{Text Box 2}

UCSF Annual revenue: \$1.4 Billion

Billing that requires discharge summary completion: $20 \%$ Lender's interest rate: $1-2 \%$

Lenders interest rate $(1-2 \%)$ on delayed billing $(20 \%)=$ $0.2-0.4 \%$ of total revenue

Assuming a 14 day delay in billing: $0.2-0.4 \%$ of total revenue $(\$ 1,400,000,000)$ for $14 / 365$ days $=\$ 107,000-\$ 215,000$

\section{Qualitative Costs}

\section{Efficiency and Physician Time}

Implementation of any new system is likely to result in initial diminished efficiency. If patient volume is stable, this may not translate into loss of revenue, but rather cause staff to change their workflow. For example, given the new inefficiency in charting, staff may spend less time on direct patient care tasks (Intravenous Catheter placement, FT placement, patient education, discharge instructions), thus increasing the qualitative costs to implementing the system.

To minimize these costs, we used a step wise phased role out starting with one pilot team, with a plan to expand to multiple teams prior to implementation on the entire medicine service. This allowed for the creation of one central and several ancillary physician champions to troubleshoot the new system to help minimize productivity losses. One of the largest concerns in the switch from voice dictation to physician-direct entry into an electronic summary is the cost of physician time. System adjustments through several pilots helped ensure that the time investment of a novice user was not significantly greater than time previously spent dictating.

\section{Quality of Documentation}

Unanticipated consequences from a switch to an electronic platform must be considered, such as the possibility of longer more redundant discharge summaries. The amount of information available for automated import will vary by institutional preference, but the recipient's access to the EMR, primary physician preference, and technologic capabilities should be considered. At UCSF we made an effort to distill the information most important to subsequent care, disabling the importation of multiple days of radiology data and instead working to create a system for discharge medication importation. As with any electronic document, the medium also lends itself to cutting and pasting, which may lead to anachronistic information carried forward from hospital progress notes earlier in the stay. ${ }^{35,36}$ The largest experience with this unintended consequence can be found in the Veteran's Affairs Health System EMR, which found that $9 \%$ of progress notes studied contained copied or duplicated text. ${ }^{37}$ The authors recommended that clear policies, programs to raise practitioner awareness, and the development of monitoring procedure be implemented coincident with electronic note-writing capabilities.

\section{Quantitative Costs}

Quantitative Costs will be highly variable across institutions, geographical areas, and software platforms as the infrastructure of existing EMRs are highly variable. The cost of implementation depends heavily on whether inpatient documentation (and thus discharge documentation) is a feature of an institutional EMR, or whether a stand-alone discharge documentation infrastructure is needed. An explanation of the differences between these types of EMRs and the importance to the cost of infrastructure implementation is further described in the following section. Rather than providing a direct accounting of costs, we have provided a tabular summary of costs that should be considered with the adoption 


\begin{tabular}{|c|c|c|c|}
\hline & $\begin{array}{l}\text { Voice } \\
\text { Dictation }\end{array}$ & $\begin{array}{l}\text { E-Discharge } \\
\text { in an EMR } \\
\text { With Inpatient } \\
\text { Documentation } \\
\text { Abilities }\end{array}$ & $\begin{array}{l}\text { E-Discharge } \\
\text { in an EMR } \\
\text { Without Inpatient } \\
\text { Documentation } \\
\text { Abilities }\end{array}$ \\
\hline \multicolumn{4}{|l|}{ Infrastructure } \\
\hline Software & $\emptyset$ & $\emptyset$ & + \\
\hline $\begin{array}{l}\text { Hardware (sufficient computers } \\
\text { and printers) }\end{array}$ & $\emptyset$ & + & + \\
\hline Network connectivity & $\emptyset$ & + & + \\
\hline Server capacity for system backup & $\emptyset$ & + & + \\
\hline Interface with current EMR & $\emptyset$ & $\emptyset$ & + \\
\hline \multicolumn{4}{|l|}{ Personnel } \\
\hline Physician champion & $\emptyset$ & + & + \\
\hline Physician training & $\emptyset$ & + & + \\
\hline Computer programmer & $\emptyset$ & + & + \\
\hline Transcription & + & $\emptyset$ & $\emptyset$ \\
\hline Deficiency tracking & + & $\emptyset$ & $\emptyset$ \\
\hline Dissemination & + & $\emptyset$ & $\emptyset$ \\
\hline \multicolumn{4}{|l|}{ Maintenance } \\
\hline Computer/printer maintenance & $\emptyset$ & + & + \\
\hline Network maintenance & $\emptyset$ & + & + \\
\hline Software add-ons and updates & + & + & + \\
\hline
\end{tabular}

of an electronic discharge summary based on the type of institutional EMR (Table 1).

\section{Infrastructure}

For most health care organizations, the transition to an EMR includes adoption of results reporting systems and computerized provider order entry; only a more select group of hospitals with a complete EMR electronically document inpatient care (eg, progress notes) through physician direct entry. While there is substantial literature regarding the benefits and pitfalls of adopting computerized order entry (CPOE), ${ }^{38,39}$ there is less attention devoted to the costs of implementing large-scale electronic documentation, including an electronic discharge summary, as opposed to paper notes or dictation. ${ }^{40-42}$ Institutions using an EMR with electronic care documentation capability have already invested in the infrastructure to implement electronic discharge documentation, and can employ it at a modest cost. For these institutions, the infrastructure cost of the transition from paper charting or dictation to direct entry by physicians lies in ensuring sufficient computers and connectivity to handle the increased computer use. On the other hand, for those institutions where the EMR lacks this capability there are few freestanding documentation platforms available for purchase. The cost of implementing such a system is high, both for the purchase of additional software and the integration of that software in to the EMR supplied by the primary vendor. Other notable infrastructure costs to consider are ensuring sufficient network connectivity, computers and printers to accommodate increased use that will come with electronic note writing as well as server support for system backups.

\section{Personnel}

Engaging the right personnel will smooth the implementation of an electronic discharge summary. In addition to dedicated user training sessions, a physician champion who can promote and monitor user training on the new platform will facilitate prompt implementation. An IT support programmer should work with the physician champion to address concerns and troubleshoot problems. Additional personnel may also be needed to track progress in discharge summary adoption, quality and efficiency. Ideally these personnel can be funneled from those who work transcribing, disseminating and tracking completion of discharge summaries, positions that will be needed in a reduced capacity.

\section{Maintenance}

Increased IT infrastructure also means increased IT maintenance and upgrades of servers, network connectivity, computers and printers. Discussions with vendors regarding costs of maintenance, upgrades and add-on features should be considered when adopting an electronic discharge summary platform.

\section{Conclusion}

While many QI initiatives have the potential to improve clinical care, resource limitations and competing priorities necessitate that hospital decision makers see the value of hospitalist driven improvements. A sound business case is the key to successfully influencing decision making and furthering necessary innovations. We have detailed the elements of a business case and applied them to a proposed innovation-the electronic discharge summary. While the cost of multifunctional EMR with full electronic care documentation may be impossible to implement given high initial costs and competing priorities, investing in an e-discharge solution has real-time benefits in the impact on patients, system improvements, qualitative benefits, and return on investment. Being able to articulate key qualitative and quantitative elements creates a sound business case that can be applied to QI initiatives in general, and assist hospitalists in garnering support and resources to continue to improve care.

\section{Acknowledgments}

The authors acknowledge Kathleen Kerr and the members of the BOOST collaborative for helping with background research and in creating the impetus for this work.

\section{Address for correspondence and reprint requests:}

Michelle Mourad, MD, 533 Parnassus Ave, Box 0131, San

Francisco, Ca. 94143; Telephone: 415-476-2264; Fax: 415-514-2094; E-mail: Michelle.Mourad@ucsf.edu Received 14 November 2009; revision received 17 May 2010; accepted 23 May 2010.

\section{References}

1. O'Leary KJ, Liebovitz DM, Feinglass J, et al. Creating a better discharge summary: Improvement in quality and timeliness using an electronic discharge summary. J Hosp Med. 2009;4(4):219-225. 
2. Kripalani S, LeFevre F, Phillips CO, Williams MV, Basaviah P, Baker DW. Deficits in communication and information transfer between hospitalbased and primary care physicians: implications for patient safety and continuity of care. JAMA. 2007;297(8):831-841.

3. Standard IM.6.10 Hospital Accredidation Standards. Oakbrook Terrace, IL: Joint Commission Resources; 2006:338-340.

4. MacDonald I. Medical Record Services, Section 482.24. In: MacDonald I, ed. The CMS Hospital Conditions of Participation. First edition. United States: Hc Pro Inc.; 2005:24-25.

5. Fair JF. Hospital discharge and death communications. Br J Hosp Med. 1989;42(1):59-61.

6. Tulloch AJ, Fowler GH, McMullan JJ, Spence JM. Hospital discharge reports: content and design. Br Med J. 1975;4(5994):443-446.

7. Roy CL, Poon EG, Karson AS, et al. Patient safety concerns arising from test results that return after hospital discharge. Ann Intern Med. 2005; 143(2):121-128.

8. Penney TM. Delayed communication between hospitals and general practitioners: where does the problem lie? BMJ. 1988;297(6640):28-29.

9. Mageean RJ. Study of "discharge communications" from hospital. Br Med J (Clin Res Ed). 1986;293(6557):1283-1284.

10. van Walraven C, Weinberg AL. Quality assessment of a discharge summary system. CMAJ. 1995;152(9):1437-1442.

11. Wilson S, Ruscoe W, Chapman M, Miller R. General practitioner-hospital communications: a review of discharge summaries. J Qual Clin Pract. 2001;21(4):104-108.

12. Carroll J. Stimulus bill spurs plans for rapid IT progress. Manag Care 2009;18(2):5-6.

13. Cucina RJ, Lindsay L, Kupfernagel H, et al. UCSF Notewriter. Copyright Regents of the University of California. 2006-2010.

14. Rao P, Andrei A, Fried A, Gonzalez D, Shine D. Assessing quality and efficiency of discharge summaries. Am J Med Qual. 2005;20(6):337-343.

15. van Walraven C, Duke SM, Weinberg AL, Wells PS. Standardized or narrative discharge summaries. Which do family physicians prefer? Can Fam Physician. 1998;44:62-69.

16. van Walraven C, Duke SM, Weinberg AL, Wells PS. Standardized or narrative discharge summaries. Which do family physicians prefer? Can Fam Physician. 1998;44:62-69.

17. van Walraven $\mathrm{C}$, Rokosh $\mathrm{E}$. What is necessary for high-quality discharge summaries? Am J Med Qual. 1999;14(4):160-169.

18. O'Leary KJ, Liebovitz DM, Feinglass J, Liss DT, Baker DW. Outpatient physicians' satisfaction with discharge summaries and perceived need for an electronic discharge summary. J Hosp Med. 2006;1(5):317-320.

19. Alderton M, Callen J. Are general practitioners satisfied with electronic discharge summaries? HIM J. 2007;36(1):7-12.

20. van Walraven C, Laupacis A, Seth R, Wells G. Dictated versus databasegenerated discharge summaries: a randomized clinical trial. CMAJ. 1999; 160(3):319-326

21. Lissauer T, Paterson CM, Simons A, Beard RW. Evaluation of computer generated neonatal discharge summaries. Arch Dis Child. 1991;66(4 Spec No):433-436.

22. Archbold RA, Laji K, Suliman A, Ranjadayalan K, Hemingway H, Timmis AD. Evaluation of a computer-generated discharge summary for patients with acute coronary syndromes. Br J Gen Pract. 1998;48(429):1163-1164.
23. The Common Wealth Fund. Why not the best org. Available at: http/ www.whynotthebest.org. Updated 2009. Accessed May 2010.

24. Greene SE, Nash DB. Pay for performance: an overview of the literature. Am J Med Qual. 2009;24(2):140-163.

25. Forster AJ, Clark HD, Menard A, et al. Adverse events among medical patients after discharge from hospital. CMAJ. 2004;170(3):345-349.

26. van Walraven C, Seth R, Austin PC, Laupacis A. Effect of discharge summary availability during post-discharge visits on hospital readmission. J Gen Intern Med. 2002;17(3):186-192.

27. Gandhi TK, Kachalia A, Thomas EJ, et al. Missed and delayed diagnoses in the ambulatory setting: a study of closed malpractice claims. Ann Intern Med. 2006;145(7):488-496.

28. Coleman EA, Mahoney E, Parry C. Assessing the quality of preparation for posthospital care from the patient's perspective: the care transitions measure. Med Care. 2005;43(3):246-255.

29. Jack BW, Chetty VK, Anthony D, et al. A reengineered hospital discharge program to decrease rehospitalization: a randomized trial. Ann Intern Med. 2009;150(3):178-187.

30. Forster AJ, Murff HJ, Peterson JF, Gandhi TK, Bates DW. Adverse drug events occurring following hospital discharge. J Gen Intern Med. 2005; 20(4):317-323.

31. Ponzurick TG, France KR, Logar CM. Referring physician satisfaction: toward a better understanding of hospital referrals. J Hosp Mark. 1998; 12(2):95-111.

32. U.S. Department of Health \& Human Services. Hospital Compare- A quality tool provided by Medicare. Available at: http://www.hospitalcompare. hhs.gov. Updated 2009. Accessed May 2010.

33. Barclays Official California Code of Regulations. Title 22. $\$ 70717$. Admission, Transfer and Discharge Policies, 2010.

34. Lawler FH, Scheid DC, Viviani NJ. The cost of medical dictation transcription at an academic family practice center. Arch Fam Med. 1998; 7(3):269-272.

35. Kuehn BM. IT vulnerabilities highlighted by errors, malfunctions at veterans' medical centers. JAMA. 2009;301(9):919-920.

36. Siegler EL, Adelman R. Copy and paste: a remediable hazard of electronic health records. Am J Med. 2009;122(6):495-496.

37. Hammond KW, Helbig ST, Benson CC, Brathwaite-Sketoe BM. Are electronic medical records trustworthy? Observations on copying, pasting and duplication. AMIA Annu Symp Proc. 2003:269-273.

38. Garg AX, Adhikari NK, McDonald H, et al. Effects of computerized clinical decision support systems on practitioner performance and patient outcomes: a systematic review. JAMA. 2005;293(10):1223-1238.

39. Koppel R, Metlay JP, Cohen A, et al. Role of computerized physician order entry systems in facilitating medication errors. JAMA. 2005;293(10):1197-1203.

40. Payne TH, Hirschmann JV, Helbig S. The elements of electronic note style. J AHIMA. 2003;74(2):68,70.

41. Embi PJ, Yackel TR, Logan JR, Bowen JL, Cooney TG, Gorman PN Impacts of computerized physician documentation in a teaching hospital: perceptions of faculty and resident physicians. J Am Med Inform Assoc. 2004;11(4):300-309.

42. Payne TH, Perkins M, Kalus R, Reilly D. The transition to electronic documentation on a teaching hospital medical service. AMIA Аnпи Symp Proc. 2006:629-633. 